Supporting Information

\title{
A Fast and Stable Photochromic Switch Based on the Opening and Closing of an Oxazine Ring
}

\author{
Massimiliano Tomasulo, ${ }^{\dagger}$ Salvatore Sortino, ${ }^{*,}$ and Françisco M. Raymo, ${ }^{\dagger}$ \\ $\dagger$ Center for Supramolecular Science, Department of Chemistry, University of Miami, 1301 Memorial Drive, Florida \\ 33146-0431; fraymo@miami.edu \\ * Dipartimento di Scienze Chimiche, Universitá di Catania, viale Andrea Doria 8, Catania, I-95125, Italy; \\ ssortino@unict.it
}

Materials and Methods. Chemicals were purchased from commercial sources and used as received with the exception of $\mathrm{MeCN}$, which was distilled over $\mathrm{CaH}_{2}$. All reactions were monitored by thin layer chromatography, using aluminum sheets coated with silica $\left(60, \mathrm{~F}_{254}\right)$. Melting points $(\mathrm{mp})$ were determined with an Electrothermal Mel-Temp apparatus and are uncorrected. Fast atom bombardment mass spectra (FABMS) were recorded with a VG Mass Lab Trio-2 spectrometer, using 3-nitrobenzyl alcohol as matrix. Nuclear magnetic resonance (NMR) spectra were recorded with either a Bruker Avance 400 or a Bruker Avance 500 spectrometer. Steady-state absorption spectra were recorded with a Varian Cary 100 Bio spectrometer, using quartz cells with a path length of $0.5 \mathrm{~cm}$. When necessary, the samples were irradiated continuously with a Mineralight UVGL-25 lamp (365 nm, $10 \mathrm{~min})$. The output power $\left(400 \mu \mathrm{W} \mathrm{cm}{ }^{-2}\right)$ was determined with a Newport 1815-C meter.

2-Phenyl-3,3'-dimethyl-3H-indole (1). A mixture of phenylhydrazine (1.1 mL, $11 \mathrm{mmol}), i$-propylphenylketone (1.5 mL, 10 mmol) and $p$-toluenesulfonic acid $(0.11 \mathrm{~g}, 0.6 \mathrm{mmol})$ was heated under reflux for $7 \mathrm{~h}$. After cooling down to ambient temperature, the mixture was diluted with a saturated aqueous solution of $\mathrm{NaHCO}_{3}(10 \mathrm{~mL})$ and extracted with $\mathrm{CHCl}_{3}(4 \times$ $10 \mathrm{~mL})$. The organic phase was dried $\left(\mathrm{MgSO}_{4}\right)$ and the solvent was evaporated under reduced pressure. The residue was dissolved in absolute EtOH $(35 \mathrm{~mL})$ and, after the addition of $\mathrm{ZnCl}_{2}$ (14 g, $0.1 \mathrm{~mol}$ ), was heated under reflux for $24 \mathrm{~h}$. After cooling down to ambient temperature, the mixture was diluted with a saturated aqueous solution of $\mathrm{NaHCO}_{3}(40$ $\mathrm{mL})$ and extracted with $\mathrm{Et}_{2} \mathrm{O}(3 \times 10 \mathrm{~mL})$. The organic phase was dried $\left(\mathrm{MgSO}_{4}\right)$ and the solvent was evaporated under reduced pressure. The residue was purified by column chromatography [ $\mathrm{SiO}_{2}: \mathrm{CH}_{2} \mathrm{Cl}_{2}$ /heptane (4:1)] to afford the product $(1.86 \mathrm{~g}, 84 \%)$ as an orange liquid. FABMS: $m / z=222$ $[\mathrm{M}]^{+} ;{ }^{1} \mathrm{H}-\mathrm{NMR}\left(500 \mathrm{MHz}, \mathrm{CDCl}_{3}\right): \delta=1.55(6 \mathrm{H}, \mathrm{s}), 7.30(1 \mathrm{H}$, d, $8 \mathrm{~Hz}), 7.34-7.40(2 \mathrm{H}, \mathrm{m}), 7.47-7.53(3 \mathrm{H}, \mathrm{m}), 7.72(1 \mathrm{H}, \mathrm{d}, 8$ $\mathrm{Hz}), 8.14-8.20(2 \mathrm{H}, \mathrm{m}) ;{ }^{13} \mathrm{C}-\mathrm{NMR}\left(100 \mathrm{MHz}, \mathrm{CDCl}_{3}\right): \delta=$ $24.7,53.5,120.7,120.9,126.0,127.7,128.3,128.4,128.5$, $130.6,132.9,147.4,183.3$.

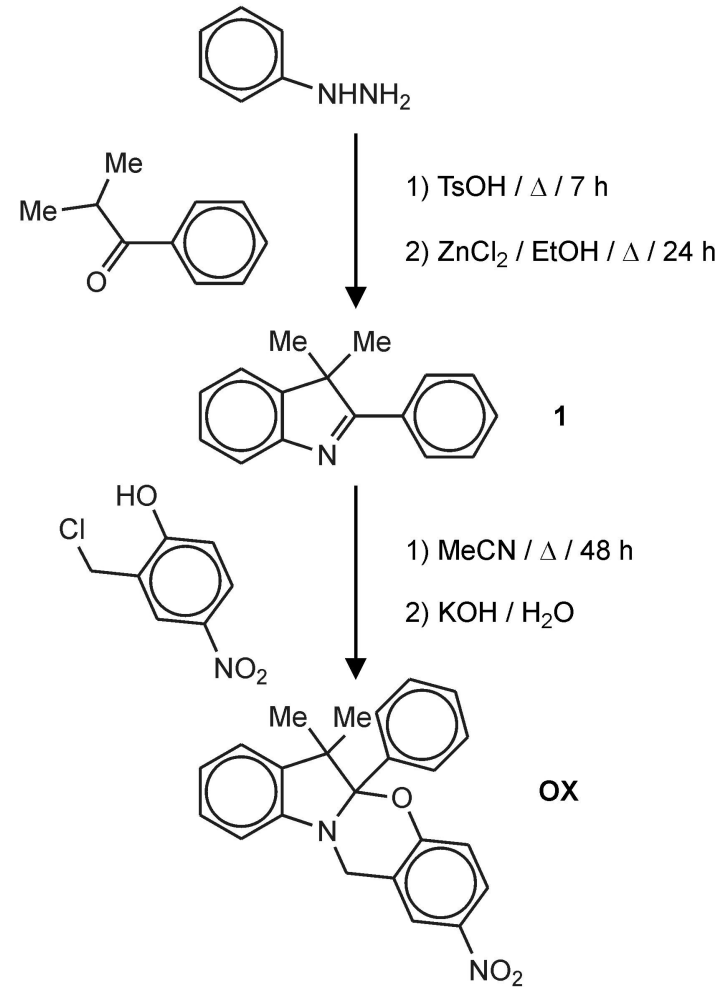

Figure S1. Synthesis of the [1,3]oxazine $\mathbf{O X}$. 
2-Nitro-5a-phenyl-6,6-dimethyl-5a,6-dihydro-12H-indolo[2,1-b][1,3]benzooxazine (OX). A solution of 1 (700 $\mathrm{mg}, 3$ $\mathrm{mmol})$ and 2-chloromethyl-4-nitrophenol $(709 \mathrm{mg}, 4 \mathrm{mmol})$ in $\mathrm{MeCN}(30 \mathrm{~mL})$ was heated under reflux for $48 \mathrm{~h}$. After cooling down to ambient temperature, the solvent was evaporated under reduced pressure and the residue was dissolved in $\mathrm{CH}_{2} \mathrm{Cl}_{2}(30 \mathrm{~mL})$. The resulting solution was washed with aqueous $\mathrm{KOH}(0.2 \mathrm{M}, 15 \mathrm{~mL})$ and $\mathrm{H}_{2} \mathrm{O}(15 \mathrm{~mL})$. The organic phase was concentrated under reduced pressure and the residue was purified by column chromatography $\left[\mathrm{SiO}_{2}\right.$ : hexane $\rightarrow$ $\mathrm{CH}_{2} \mathrm{Cl}_{2} /$ hexane (1:1)] to give $\mathbf{O X}(680 \mathrm{mg}, 58 \%)$ as a white solid. $\mathrm{mp}=176{ }^{\circ} \mathrm{C}$; FABMS: $m / z=372[\mathrm{M}]^{+} ;{ }^{1} \mathrm{H}-\mathrm{NMR}(400$ $\left.\mathrm{MHz}, \mathrm{CDCl}_{3}\right): \delta=0.89(3 \mathrm{H}, \mathrm{s}), 1.60(3 \mathrm{H}, \mathrm{s}), 4.53(1 \mathrm{H}, \mathrm{d}, 11 \mathrm{~Hz}), 4.63(1 \mathrm{H}, \mathrm{d}, 11 \mathrm{~Hz}), 6.73(1 \mathrm{H}, \mathrm{d}, 8 \mathrm{~Hz}), 6.86-6.94(2 \mathrm{H}$, m), 7.16-7.19 (2H, m), 7.38-7.42 (3H, m), 7.54-7.65 (2H, m), 7.92-7.94 (2H, m); ${ }^{13} \mathrm{C}-\mathrm{NMR}\left(100 \mathrm{MHz}, \mathrm{CDCl}_{3}\right): \delta=18.6$, 27.9, 41.0, 49.9, 105.5, 109.2, 118.3, 120.3, 121.0, 122.6, 123.3, 123.9, 127.9, 128.2, 128.8, 129.1, 136.1, 137.9, 141.4, 147.0, 159.3 .

Laser Flash Photolysis. Solutions of $\mathbf{O X}\left(0.1 \mathrm{mM}, 22 \pm 2^{\circ} \mathrm{C}\right)$ in $\mathrm{MeCN}$ were illuminated with the third harmonic of a $\mathrm{Nd}-$ YAG Continuum Surelite II-10 laser (355 nm, $6 \mathrm{~ns}, \sim 8 \mathrm{~mJ})$, using quartz cells with a path length of $1.0 \mathrm{~cm}$. The excited solutions were analyzed with a Luzchem Research mLFP-111 apparatus with an orthogonal pump/probe configuration. The probe source was a ceramic xenon lamp coupled to quartz fiber-optical cables. The laser pulse and the mLFP-111 system were synchronized by a Tektronix TDS 3032 digitizer, operating in pre-trigger mode. The signals from a compact Hamamatsu photomultiplier were initially captured by the digitizer and then transferred to a personal computer, controlled by Luzchem Research software operating in the National Instruments LabView 5.1 environment. The energy of the laser pulse was measured at each shot with a SPHD25 Scientech pyroelectric meter.

Determination of the Quantum Yield for the Transformation of $\boldsymbol{O X}$ into IN. The quantum yield $\left(\Phi_{\mathrm{IN}}\right)$ for the photoinduced conversion of $\mathbf{O X}$ into IN was determined with equation (1), using an optically-matched MeCN solution of benzophenone as standard. The quantum yield $\left(\Phi_{\mathrm{BE}}\right)$ for the intersystem crossing of benzophenone is unity and the molar extinction coefficient $\left(\varepsilon_{\mathrm{BE}}\right)$ for its triplet absorption at $520 \mathrm{~nm}$ is $6.5 \mathrm{mM}^{-1} \mathrm{~cm}^{-1}$. S1 The molar extinction coefficient $\left(\varepsilon_{\mathrm{IN}}\right)$ of $\mathbf{I N}$ at 440 $\mathrm{nm}$ was estimated to be $c a .22 \mathrm{mM}^{-1} \mathrm{~cm}^{-1}$ from the absorption spectrum ( $c$ in Figure 3) of potassium $p$-nitrophenolate. The terms $\chi_{\mathrm{IN}}$ and $\chi_{\mathrm{BE}}$ in equation (1) are the slopes of the linear portions of plots of the photoinduced absorbance changes, measured at the end of the pulse for IN and the benzophenone triplet respectively, against the energy of the laser pulse.

$$
\Phi_{\mathrm{IN}}=\frac{\chi_{\mathrm{IN}} \varepsilon_{\mathrm{BE}} \Phi_{\mathrm{BE}}}{\chi_{\mathrm{BE}} \varepsilon_{\mathrm{IN}}}
$$

Determination of the Quantum Yield of Singlet Oxygen. The evolution of singlet oxygen $\left({ }^{1} \Delta_{\mathrm{g}}\right)$ in the course of the photoinduced transformation of $\mathbf{O X}$ into IN was monitored by luminescence measurements in air-saturated MeCN. Upon laser excitation of $\mathbf{O X}$, the emission of singlet oxygen at $1.27 \mu \mathrm{m}$ was probed orthogonally to the exciting beam with a preamplified (low impedance) Ge-photodiode (Hamamatsu EI-P, $300 \mathrm{~ns}$ resolution) maintained at $-196^{\circ} \mathrm{C}$ and coupled to a long-pass silicon filter $(>1.1 \mu \mathrm{m})$ and an interference filter $(1.27 \mu \mathrm{m})$. The temporal profile of the luminescence was fitted to a single-exponential decay function with the exclusion of the initial portion of the plot, which is affected by the scattered excitation. The luminescence at initial time was extrapolated from the curve fitting. The quantum yield $\left(\Phi_{\Delta 1}\right)$ of singlet oxygen was determined with equation (2), using an optically-matched and air-saturated $\mathrm{MeCN}$ solution of benzophenone as standard. The quantum yield $\left(\Phi_{\Delta 2}\right)$ of singlet oxygen formed upon excitation of benzophenone is 0.37 . ${ }^{\mathrm{S} 2}$ The terms $\chi_{1}$ and $\chi_{2}$ in equation (2) are the slopes of the linear portions of plots of the singlet-oxygen luminescence, determined at initial time upon excitation of $\mathbf{O X}$ and benzophenone respectively, against the energy of the laser pulse.

$$
\Phi_{\Delta 1}=\frac{\chi_{1} \Phi_{\Delta 2}}{\chi_{2}}
$$

S1 Bensasson, R. V.; Gramain, J. C. J. Chem. Soc. Faraday 1980, 76, 1801-1810.

S2 Wilkinson, F.; Helman, W. P.; Ross, A. B. J. Phys. Chem. Ref. Data 1993, 22, 113-262. 